Sains Malaysiana 50(7)(2021): 2109-2121

http://doi.org/10.17576/jsm-2021-5007-24

\title{
Risk Analysis of the Copula Dependent Aggregate Discounted Claims with Weibull Inter-Arrival Time
}

(Analisis Risiko Agregat Tuntutan Terdiskaun yang Bersandar Secara Kopula dengan antara Waktu Ketibaan Bertaburan Weibull)

Siti Norafidah Mohd Ramli, Sharifah FARAh Syed Yusoff AlHabshi* \& NuR Atikah Mohamed Rozali

\section{ABSTRACT}

We model the recursive moments of aggregate discounted claims, assuming the inter-claim arrival time follows a Weibull distribution to accommodate overdispersed and underdispersed data set. We use a copula to represent the dependence structure between the inter-claim arrival time and its subsequent claim amount. We then use the Laplace inversion via the Gaver-Stehfest algorithm to solve numerically the first and second moments, which takes the form of a Volterra integral equation (VIE). We compute the average and variance of the aggregate discounted claims under the FarlieGumbel-Morgenstern (FGM) copula and conduct a sensitivity analysis under various Weibull inter-claim parameters and claim-size parameters. The comparison between the equidispersed, overdispersed and underdispersed counting processes shows that when claims arrive at times that vary more than is expected, insured lives can expect to pay higher premium, and vice versa for the case of claims arriving at times that vary less than expected. Upon comparing the Weibull risk process with an equivalent Poisson process, we also found that copulas with a wider range of dependency parameter such as the Frank and Heavy Right Tail (HRT), have a greater impact on the value of moments as opposed to modeling under FGM copula with weak dependence structure.

Keywords: FGM copula; Gaver-Stehfest algorithm; Laplace transform; Volterra integral equation; Weibull count model

\section{ABSTRAK}

Kajian ini memodelkan momen rekursif tuntutan agregat terdiskaun, dengan andaian bahawa waktu ketibaan antara tuntutan mengikut taburan Weibull bagi memenuhi keperluan set data yang terlebih atau terkurang serak. Kajian ini menggunakan kopula untuk mewakili struktur kebersandaran antara waktu ketibaan antara tuntutan dan jumlah tuntutan berikutnya. Kajian ini menggunakan songsangan Laplace melalui algoritma Gaver-Stehfest untuk menyelesaikan secara berangka momen pertama dan kedua dalam bentuk persamaan kamiran Volterra (VIE). Kajian ini menghitung purata dan varians tuntutan agregat terdiskaun di bawah kopula Farlie-Gumbel-Morgenstern (FGM) dan analisis kepekaan dijalankan dengan mengubah parameter Weibull, waktu ketibaan antara tuntutan dan parameter saiz tuntutan. Perbandingan antara proses pengiraan sama serakan, terlebih serakan atau terkurang serakan menunjukkan bahawa apabila tuntutan tiba pada waktu yang bervariasi lebih dari yang dijangkakan, pihak yang diinsurans perlu membayar premium yang lebih tinggi dan sebaliknya bagi kes tuntutan yang tiba pada waktu yang bervariasi kurang dari yang dijangkakan. Selain perbandingan proses risiko Weibull dengan proses Poisson yang setara, kajian ini juga mendapati bawah kopula dengan julat parameter kebersandaran yang lebih luas seperti Frank dan Heavy Right Tail (HRT), memberi kesan yang lebih besar kepada nilai momen berbanding di bawah kopula FGM dengan struktur kebersandaran yang lemah.

Kata kunci: Algoritma Gaver-Stehfest; kopula FGM; model kira Weibull; persamaan kamiran Volterra; transformasi Laplace

\section{INTRODUCTION}

As reported in MunichRe (2018), while the amount of overall and insured losses seem to max out every 3 years (year 2005, 2008 and 2011), the trend did not repeat itself during the year 2014. However, the losses spiked up again after six years, and 2017 became the year with the second highest losses since the year 2005. Hence, the independent assumption between claims size and inter-claim arrival time in a classical risk model, as heavily covered in Delbaen 
and Haezendonck (1987), Waters (1983) and Yang and Zhang (2001) may no longer be appropriate for insurance risk portfolio modeling. Recent studies have employed the dependence assumption through the dependent frequencyseverity modeling under automobile insurance (Shi et al. 2015), while Kularatne et al. (2020) examined the suitable bivariate model through Archimedean copula to capture the dependence structure in general and life insurance modeling.

Two general approaches proposed in modeling the dependency between claims severity and frequency are the conditional probability decomposition approach and the copula approach (Garrido et al. 2016). The first approach decomposes the joint probability distribution between the claims severity and frequency into a product of conditional probabilities and then predicts average claims severity using a regression model with the claims frequency as a covariate (Shi et al. 2015). On the other hand, the copula approach links the joint distribution of the claims severity and claims frequency through a copula. Additionally, a copula can also be applied in modeling the joint distribution between claims severity and frequency margins that follow generalized linear regression models so that covariates of the marginals can be taken into account when predicting total loss (Hua 2015; Krämer et al. 2013). Besides insurance portfolio, copula have also been applied to capture dependency between macroeconomic variables in bond pricing (Mohd Ramli \& Jang 2020) and several equity markets (Shamiri et al. 2011). Apart from that, copula has also been used to characterize the joint probability distribution between rainfall duration and severity under hydrologic events (Kamaruzaman et al. 2019; Tosunoglu \& Kisi 2016).

Using renewal theory arguments and conditioning on the first claim arrival, Léveillé and Garrido (2001) derived the $m$-th recursive aggregate moment, assuming independence between claim arrival time and its severity. The technique was used in Bargès et al. (2011), to derive a closed-form solution of the $m$-th moment for the Poisson counting process using the Laplace transform, with an FGM copula capturing the dependency between interclaim arrival time and severity. It has also been applied to a dependent Sparre-Andersen risk process that relaxes the independent assumption between the $j$-th inter-claim arrival time, $W_{j}$, and the $j$-th claim severity, $X_{j}$ (Woo \& Cheung 2013). Mohd Ramli and Jang (2014) then extended the works of Bargès et al. (2011) and Léveillé and Garrido (2001) by explicitly finding the Neumann series expressions of the moments, which are expressed in the form of a VIE.

The previously mentioned studies illustrated the numerical examples using the Poisson process, i.e. an equidispersed Weibull count process, which has an equal mean and variance. The Poisson counting process is commonly used to represent event occurrence due to its simple corresponding exponentially distributed interclaim arrival time, which can also be seen in studies related to ruin measures (Albrecher et al. 2020). However, it is only adequate if the data satisfies the restrictive assumption of equidispersion; that is, the variance of the data is equal to its mean. Shi et al. (2015) illustrated that the Poisson process is insufficient to capture the overdispersion present in the automobile insurance data and proposed the use of Negative Binomial (NB) model. However, the NB model is unable to accommodate underdispersed data, and the closed-form of hazard function could not be obtained. The Weibull count model is a better alternative not only because the model can handle both overdispersed and underdispersed data sets, but it also nests commonly used count models, including the Poisson and the NB distributions (McShane et al. 2008). The Weibull count process has also been used to predict the number of goals scored in a football match (Boshnakov et al. 2017). Combined with a copula to capture the dependency between the goals scored by the two opposing teams, the Weibull count model is found to be a better fit than a Poisson count model with independent assumption. Additionally, the Weibull count model also allows for nonconstant hazard rates that vary according to the duration of the inter-waiting time. This is useful in modeling the arrival of unexpected random shocks that lead to the breakdown of many engineering systems as seen in Liu (2019).

In this study, we propose to use Weibull interarrival time distribution to handle both overdispersed and underdispersed data sets. We then model the dependence of inter-claim arrival time and claims size, represented by an FGM copula. The moments of aggregate discounted claims are then expressed in VIE form using the numerical Laplace inversion via the Gaver-Stehfest algorithm Stehfest (1970) to allow for numerical solutions. We organize the remainder of this article as follows: In the next section, we introduce the continuous time renewal risk model with the Weibull counting process. We present FGM copula to model the dependency between the interclaim arrival time and the claims size. Subsequent section 
describes the recursive moments expressions in VIE form and the steps taken to numerically solve the equations using Laplace inversion via the Gaver-Stehfest algorithm. The following section illustrates the numerical verification of the inverted expression, the comparison of moments and premium computation under the underdispersed, equidispersed and overdispersed scenarios, as well as the sensitivity analysis on the moments. We also compare the results using Frank and HRT copula under the exponential inter-waiting time. We then conclude in the last section.

\section{MATERIALS AND METHODS}

\section{CLAIMS MODEL SETUP}

We define the aggregate discounted claims, $\underline{Z}=\{Z(t)\}_{t \geq 0}$, with a deterministic instantaneous rate of net interest $\delta$ as:

$$
\mathrm{Z}(t)= \begin{cases}\sum_{i=1}^{N(t)} e^{-\delta T_{i}} X_{i} & \text { if } N(t)>0 \\ 0 & \text { if } N(t)=0,\end{cases}
$$

where $X, i=1,2, \ldots$ is a continuous, nonnegative, independent and identically distributed (i.i.d.) random variable that represents claims size occurring at time $T_{i}$, $i=1,2, \ldots, N(t)$

\section{WEIBULL COUNT MODEL}

The counting process $\underline{N}=\{N(t)\}_{t \geq 0}$ suggested in this study is a basic Weibull counting process, whereby the corresponding continuous random variable of the interclaim arrival time, $W_{j}$ follows a Weibull distribution and is defined as:

$$
W_{j}= \begin{cases}T_{j} & \text { for } j=1 \\ T_{j}-T_{j-1} & \text { for } j=2,3, \ldots\end{cases}
$$

Each pair of the joint variables forms a sequence of i.i.d. random vectors $\left\{\left(X_{j}, W_{j}\right)\right\}_{j \in N^{*}}$

From (12) and (14) of McShane et al. (2008), the mean and variance of a Weibull count model with shape parameter, and scale parameter $\lambda>0$, and scale parameter $\beta>0$, as:

$$
\begin{gathered}
\mathrm{E}[N(t)]=\sum_{n=1}^{\infty} \sum_{j=n}^{\infty} \frac{n(-1)^{j+n}\left(t^{\lambda} / \beta\right)^{j} \tau_{j}^{n}}{\Gamma(\lambda j+1)}, \\
\operatorname{Var}[N(t)]=\mathrm{E}\left[N^{2}(t)\right]-\mathrm{E}^{2}[N(t)] \\
=\sum_{n=2}^{\infty} \sum_{j=n}^{\infty} \frac{n^{2}(-1)^{j+n}\left(t^{\lambda} / \beta\right)^{j} \tau_{j}^{n}}{\Gamma(\lambda j+1)}-\left(\sum_{n=1}^{\infty} \sum_{j=n}^{\infty} \frac{n(-1)^{j+n}\left(t^{\lambda} / \beta\right)^{j} \tau_{j}^{n}}{\Gamma(\lambda j+1)}\right)^{2},
\end{gathered}
$$

where $\tau_{j}^{n}= \begin{cases}\frac{\Gamma(\lambda j+1)}{\Gamma(j+1)}, & \text { for } n=0, j=0,1,2, \ldots \\ \sum_{m=n-1}^{j-1} \tau_{j}^{n-1} \frac{\Gamma(\lambda j-\lambda m+1)}{\Gamma(j-m+1)}, & \text { for } n=1,2,3, \ldots, j=n, n+1, n+2, \ldots,\end{cases}$

in which the parameter $n$ denotes the number of events that occur in the interval $(0, t]$. The Weibull count model is based upon an assumed Weibull inter-arrival time process which could accommodate greater, equal or less variability in a data set than predicted through the shape parameter being less than, equal to or greater than 1, respectively. The Weibull count model nests the Poisson or Negative Binomial Count Model as special cases.

COPULA

We allow for dependency between the claim size, $X_{j}$ and the inter-arrival time, $W_{j}$, captured by the FGM copula, since the independence assumption between the two marginals as covered in numerous past literature may no longer be appropriate. The probability density functions (pdf) of the copula is given by

$$
c_{\theta}^{F G M}\left(F_{X}(x), F_{W}(w)\right)=1+\theta\left(1-2 F_{X}(x)\right)\left(1-2 F_{W}(w)\right),
$$

where $\theta \in[-1,1]$ represents the dependence parameter (Balakrishna \& Lai 2009; Nelsen 2006). In relation to this study, when the marginals are negatively correlated (i.e. when $\theta \in[-1,0)$ ), a large/small claim amount will occur following a short/long inter-arrival claim time. On the other hand, a positively correlated marginals (i.e. when $\theta \in(0,1])$ imply that a large/small claim amount will occur following a long/short inter-arrival claim time. Other than for simplicity of illustration, the FGM copula was chosen for comparison with previous studies to ensure that the equation derived and Gaver-Stehfest algorithms used return values as consistent as given by the Neumann series and the Laplace transform derived in Mohd Ramli and Jang (2014) and Bargès et al. (2011), respectively. Nonetheless, its simplicity and analytical tractability make the FGM copula a popular choice in extreme value analysis and risk management (Mao \& Yang 2015).

Additionally, we also use the Frank copula and the HRT copula in comparison with the FGM copula assuming $\lambda=1$, i.e. the case of exponential inter-waiting time. Both FGM and Frank copula allow for both positive and negative dependency between the marginals. The Frank copula can capture a wider range of dependency as opposed to FGM (Tosunoglu \& Kisi 2016). HRT copula, on the other hand is only able to model positive dependency 
and therefore is appropriate in modeling upper tail dependency, particularly in extreme events (Venter 2002). The pdf of the Frank and HRT copula are given as:

$$
c_{\theta}^{\text {Frank }}\left(F_{X}(x), F_{W}(w)\right)=\frac{(\theta-1) \log _{\theta}\left(\theta^{F_{X}(x)+F_{W}(w)}\right)}{\left[\theta-1+\left(\theta^{F_{X}(x)}-1\right)\left(\theta^{F_{W}(w)}-1\right)\right]^{2}}, \theta \in(0, \infty),
$$

$$
c_{\theta}^{H R T}\left(F_{X}(x), F_{W}(w)\right)=\left(1+\frac{1}{\theta}\right)\left[\left(1-F_{X}(x)\right)^{-\frac{1}{\theta}}+\left(1-F_{W}(w)\right)^{-\frac{1}{\theta}}-1\right]^{-(\theta+2)}
$$

$$
\times\left[\left(1-F_{X}(x)\right)\left(1-F_{W}(w)\right)\right]^{-\left(1+\frac{1}{\theta}\right)}, \theta \in(0, \infty)
$$

\section{RECURSIVE MOMENTS OF AGGREGATE DISCOUNTED}

\section{CLAIMS}

We write the general form of the $m$-th moment of aggregate discounted claims $Z(t)$ as:

$$
\begin{aligned}
& \mu_{z}^{(m)}(T)=\mathrm{E}\left[Z^{m}(T)\right]=\int_{0}^{T} f_{W}(w) e^{-m \delta w} \mathrm{E}\left(X^{m} \mid W=w\right) d w \\
& +\int_{0}^{T} f_{W}(w) e^{-m \delta w} \mu_{z}^{(m)}(T-w) d w \\
& +\sum_{j=1}^{m-1}\left(\begin{array}{c}
m \\
j
\end{array}\right) \int_{0}^{T} f_{W}(w) e^{-m \delta w} \mathrm{E}\left(X^{j} \mid W=w\right) \mu_{z}^{(m-j)}(T-w) d w
\end{aligned}
$$

Given the conditional moment of claims size and given the claim arrival time for $m \geq 1, \mathrm{E}\left(X^{m} \mid W=w\right)=\int_{0}^{\infty} x^{m}$ $f_{X \mid W=w}(x) d x,(6)$ becomes:

$$
\begin{aligned}
& \mu_{z}^{(m)}(T)=\int_{0}^{T} \int_{0}^{\infty} e^{-m \delta w} x^{m} f_{W}(w) f_{X \mid W=w}(x) d x d w \\
& +\int_{0}^{T} f_{W}(w) e^{-m \delta w} \mu_{z}^{(m)}(T-w) d w \\
& +\sum_{j=1}^{m-1}\left(\begin{array}{l}
m \\
j
\end{array}\right) \int_{0}^{T} \int_{0}^{\infty} e^{-m \delta w} x^{j} f_{W}(w) f_{X \mid W=w}(x) \mu_{z}^{(m-j)}(T-w) d x d w \\
& =\int_{0}^{T} \int_{0}^{\infty} e^{-m \delta w} x^{m} f_{X, W}(x, w) d x d w+\int_{0}^{T} f_{W}(w) e^{-m \delta w} \mu_{z}^{(m)}(T-w) d w \\
& +\sum_{j=1}^{m-1}\left(\begin{array}{l}
m \\
j
\end{array}\right) \int_{0}^{T} \int_{0}^{\infty} e^{-m \delta w} x^{j} f_{X, W}(x, w) \mu_{z}^{(m-j)}(T-w) d x d w .
\end{aligned}
$$

The dependence structure between the claims size, $X_{j}$, and the inter-claim arrival time, $W_{j}$ is captured by a copula which appears in (7) via the joint pdf

$$
f_{X, W}(x, w)=c_{\theta}\left(F_{X}(x) F_{W}(w)\right) f_{X}(x) f_{W}(w),
$$

where $c_{\theta}\left(F_{X}(x) F_{W}(w)\right)$ is the pdf of a copula. This joint pdf can be specified using the marginal densities and a copula density (see Sklar's Theorem in (Nelsen 2006)).

Assuming Weibull inter-claim time with pdf $f_{W}(w)=\frac{\lambda}{\beta^{\lambda}} w^{\lambda-1} e^{-(w / \beta)^{\lambda}}, \lambda>0$, the expression of the first moment becomes

$$
\begin{aligned}
\mu_{z}^{(1)}(T) & =\int_{0}^{T} \int_{0}^{\infty} e^{-\delta w} x f_{X, W}(x, w) d x d w \\
& +\int_{0}^{T} e^{-\delta w} f_{W}(w) \mu_{z}^{(1)}(T-w) d w \\
& =\int_{0}^{T} \int_{0}^{\infty} e^{-\delta w} x f_{X, W}(x, w) d x d w \\
& +\frac{\lambda}{\beta^{\lambda}} \int_{0}^{T} e^{-\delta w} w^{\lambda-1} e^{-\left(\frac{w}{\beta}\right)^{\lambda}} \mu_{z}^{(1)}(T-w) d w .
\end{aligned}
$$

Note that the inter-claim time follows exponential distribution with mean $\beta$ when $\lambda=1$, giving us a risk portfolio with a Poisson counting process claims occurrence. We let $g(T)=\int_{0}^{T} \int_{0}^{\infty} e\left(^{-\delta w}\right) x f_{X, W}(x, w) d x d w$ and $k^{(1)}(T-w)=e^{-\delta(T-w)}(T-w)^{\lambda-1} e^{-\left(\frac{T-w}{\beta}\right)^{\lambda}}$ in (8). Using the property of the convolution integral, which states $\int_{0}^{a}$ $\eta(a-b) \gamma(b) d b=\int_{0}^{a} \eta(b) \gamma(a-b) d b,(8)$ can be written as the following:

$$
\begin{aligned}
\mu_{z}^{(1)}(T) & =g(T)+\frac{\lambda}{\beta^{\lambda}} \int_{0}^{T} e^{-\delta(T-w)}(T-w)^{\lambda-1} e^{-\left(\frac{T-w}{\beta}\right)^{\lambda}} \mu_{z}^{(1)}(w) d w \\
& =g(T)+\frac{\lambda}{\beta^{\lambda}} \int_{0}^{T} k(T-w) \mu_{z}^{(1)}(w) d w .
\end{aligned}
$$

We repeat the previous steps to derive the expression of the second moment for the risk portfolio $Z$ under Weibull interclaim waiting time. Substituting $m=2$ in (7), we obtain the integral of the second recursive moment as follows:

$$
\begin{aligned}
\mu_{z}^{(2)}(T) & =\int_{0}^{T} \int_{0}^{\infty} e^{-2 \delta w} x^{2} f_{X, W}(x, w) d x d w \\
& +\int_{0}^{T} \int_{0}^{\infty} 2 e^{-2 \delta w} x f_{X, W}(x, w) \mu_{z}^{(1)}(T-w) d x d w \\
& +\int_{0}^{T} e^{-2 \delta w} f_{W}(w) \mu_{z}^{(2)}(T-w) d w \\
& =\int_{0}^{T} \int_{0}^{\infty} e^{-2 \delta w} x^{2} f_{X, W}(x, w) d x d w \\
& +\int_{0}^{T} \int_{0}^{\infty} 2 e^{-2 \delta w} x f_{X, W}(x, w) \mu_{z}^{(1)}(T-w) d x d w \\
& +\frac{\lambda}{\beta^{\lambda}} \int_{0}^{T} e^{-2 \delta w} w^{\lambda-1} e^{-\left(\frac{w}{\beta}\right)^{\lambda}} \mu_{z}^{(2)}(T-w) d w .
\end{aligned}
$$


Let $k^{(2)}(T-w)=e^{-2 \delta(T-w)}(T-w)^{\lambda-1}, g^{(2)}(T)=\int_{0}^{T} \int_{0}^{\infty} e^{-2 \delta w} x^{2} f_{X, W}$ $(x, w) d x d w$ and $c(T-w)=\int_{0}^{\infty} 2 e^{-2 \delta(T-w)} f_{X, W}(x, T-w) \mathrm{d} x$. By the property of convolution integral,

$$
\begin{aligned}
\mu_{z}^{(2)}(T) & =g^{(2)}(T)+\int_{0}^{T} c(T-w) \mu_{z}^{(1)}(w) d x d w \\
+ & \frac{\lambda}{\beta^{\lambda}} \int_{0}^{T} e^{-2 \delta(T-w)}(T-w)^{\lambda-1} e^{-\left(\frac{T-w}{\beta}\right)^{\lambda}} \mu_{z}^{(2)}(w) d w \\
\quad= & g^{(2)}(T)+\int_{0}^{T} c(T-w) \mu_{z}^{(1)}(w) d w+\frac{\lambda}{\beta^{\lambda}} \int_{0}^{T} k^{(2)}(T-w) \mu_{z}^{(2)}(w) d w .
\end{aligned}
$$

The recursive aggregate moments in (9) and (11) take the form of a non-homogeneous VIE of the second kind, whose general form is given by:

$$
\phi(T)=\Phi(T)+\int_{a}^{T} \chi(T, w) \phi(w) d w,
$$

where $\Phi(T) \neq 0$ is a continuous function in the region $a \leq T$ and $\chi(T, w)$ is the kernel function in the region $a \leq w \leq T$. When both $\Phi(T)$ and $\chi(T, w)$ are continuous, $\phi(T)$ will be unique and continuous. In mapping (9) and (11) to the general form of the VIE, we can see that $\Phi(T)$ corresponds to $g(T)$ while the kernel function $\chi(T, w)$ corresponds to $k(T, w)$ in (9). Similarly, the continuous function $\Phi(T)$ corresponds to the component $g^{(2)}(T)+$ $\int_{0}^{T} c(T-w) \mu_{z}^{(1)}(w) d w$ in (11), whereas the kernel function $\chi(T, w)$ corresponds to the $k^{(2)}(T-w)$. Often found in the study of electromagnetic field and viscoelasticity, the VIE has also been applied in operational risk modeling, demographic study, and insurance mathematics.

\section{LAPLACE INVERSION OF THE RECURSIVE MOMENTS}

The VIE form of the recursive moments of aggregate discounted claims in (9) and (11) with Weibull inter-claim arrival time proposed in this study allows the recursive equations to be solved numerically using the Laplace transform and the Gaver-Stehfest(G-S) algorithm. The steps to numerically solve the equations are as follows:

Let $G(\rho), C(\rho), K(\rho)$, and $\Psi(\rho)$ denote the Laplace transform of $\mathrm{g}(T), c(T), k(T)$, and $\psi(T)$, respectively. The convolution integral of two functions $k(T)$ and $\psi(T)$ is given by $\int_{0}^{T} k(T-w) \psi(w) d w$ and its Laplace transform $L\left\{\left(k^{*} \psi\right)(T)\right\}=K(\rho) \Psi(\rho)$.

Taking the Laplace transform of (9), we obtain

$$
\begin{gathered}
\mathcal{L}\left(\mu_{z}^{(1)}(T)\right)=\mathcal{L}(g(T))+\frac{\lambda}{\beta^{\lambda}} \mathcal{L}\left(\int_{0}^{T} k(T-w) \mu_{z}^{(1)}(w) d w\right) \\
=G(\rho)+\frac{\lambda}{\beta^{\lambda}} K(\rho) \mathcal{L}\left(\mu_{z}^{(1)}(T)\right)=\frac{G(\rho)}{1-\frac{\lambda}{\beta^{\lambda}} K(\rho)}
\end{gathered}
$$

and its inverse Laplace transform:

$$
\mu_{z}^{(1)}(T)=\mathcal{L}^{-1}\left(\frac{G(\rho)}{1-\frac{\lambda}{\beta^{\lambda}} K(\rho)}\right)
$$

Equation (14) is also the first moment function of the risk portfolio. Similarly, we obtain the second moment function by taking the inverse of the Laplace transform of (11).

$$
\begin{aligned}
& \mathcal{L}\left(\mu_{z}^{(2)}(T)\right)= \mathcal{L}\left(g^{(2)}(T)\right)+\mathcal{L}\left(\int_{0}^{T} c(T-w) \mu_{z}^{(1)}(w) d x d w\right) \\
&+\frac{\lambda}{\beta^{\lambda}} \mathcal{L}\left(\int_{0}^{T} k^{(2)}(T-w) \mu_{z}^{(2)}(w) d w\right) \\
&= G^{(2)}(\rho)+C(\rho) \mathcal{L}\left(\mu_{z}^{(1)}(T)\right)+\frac{\lambda}{\beta^{\lambda}} K^{(2)}(\rho) \mathcal{L}\left(\mu_{z}^{(2)}(T)\right)=\frac{G^{(2)}(\rho)+C(\rho) \mathcal{L}\left(\mu_{z}^{(1)}(T)\right)}{1-\frac{\lambda}{\beta^{\lambda}} K^{(2)}(\rho)} \\
& \mu_{z}^{(2)}(T)=\mathcal{L}^{-1}\left(\frac{G^{(2)}(\rho)+C(\rho) \mathcal{L}\left(\mu_{z}^{(1)}(T)\right)}{1-\frac{\lambda}{\beta^{\lambda}} K^{(2)}(\rho)}\right) .
\end{aligned}
$$

When $\lambda=1$, the inter-claim time is exponentially distributed with mean $\beta$. The kernel function $k^{(\mathrm{m})}(T-w)$ is given by:

$$
k^{(m)}(T-w)=e^{-\left(m \delta+\frac{1}{\beta}\right)(T-w)},
$$

and the Laplace transform of $k^{(\mathrm{m})}(T)$ with respect to $T$ is:

$$
K^{(m)}(\rho)=\frac{1}{1 / \beta+m \delta+\rho} .
$$

Therefore, the first and second moments can be simplified into:

$$
\begin{aligned}
& \mu_{z}^{(1)}(T)=\mathcal{L}^{-1}\left(\frac{G(\rho)}{1-\frac{1}{\beta} K(\rho)}\right)=\mathcal{L}^{-1}\left(\frac{G(\rho)}{1-\frac{1}{\beta}\left(\frac{1}{1 / \beta+\delta+\rho}\right)}\right) \\
& =\mathcal{L}^{-1}\left(G(\rho)+\frac{G(\rho)}{\beta(\delta+\rho)}\right)=g(T)+\frac{1}{\beta} \mathcal{L}^{-1}\left(\frac{1}{\delta+\rho} G(\rho)\right), \\
& \text { and } \mu_{z}^{(2)}(T)=\mathcal{L}^{-1}\left(\frac{G^{(2)}(\rho)+C(\rho) \mathcal{L}\left(\mu_{z}^{(1)}(T)\right)}{1-\frac{1}{\beta} K^{(2)}(\rho)}\right)=\mathcal{L}^{-1}\left(\frac{G^{(2)}(\rho)+C(\rho) \mathcal{L}\left(\mu_{z}^{(1)}(T)\right)}{1-\frac{1}{\beta}\left(\frac{1}{1 / \beta^{+\delta+\rho}}\right)}\right) \\
& =\mathcal{L}^{-1}\left(G^{(2)}(\rho)+C(\rho) \mathcal{L}\left(\mu_{z}^{(1)}(T)\right)+\frac{G^{(2)}(\rho)+C(\rho) \mathcal{L}\left(\mu_{z}^{(1)}(T)\right)}{\beta(\delta+\rho)}\right) \\
& =g^{(2)}(T)+\mathcal{L}^{-1}\left(C(\rho) \mathcal{L}\left(\mu_{z}^{(1)}(T)\right)\right) \\
& +\mathcal{L}^{-1}\left(\frac{G^{(2)}(\rho)+C(\rho) \mathcal{L}\left(\mu_{z}^{(1)}(T)\right)}{\beta(\delta+\rho)}\right) \text {. }
\end{aligned}
$$


Notice that (18) and (19) are equivalent to (16) and (17) in Mohd Ramli and Jang (2014), as well as (10) and (16) in Bargès et al. (2011). Had we use the Neumann series expansion as in Mohd Ramli and Jang (2014), the number of integrals would increase with the order of moments even with a simple Poisson counting process. This would cause the computation of moments to be less efficient and less robust due to computing error as we attempt to compute the value of higher moments for a Weibull inter-waiting time when $\lambda \neq 1$. Hence, we will work with numerical inversion of the Laplace transform instead of obtaining the explicit expressions.

\section{THE GAVER-STEHFEST ALGORITHM}

The numerical inversion of the Laplace transform of the moments as given by (14) and (15) will be solved by utilizing the Gaver-Stehfest algorithm Stehfest (1970) when $\lambda \neq 1$. The algorithm has been used to solve Laplace equations arising in many fields including geophysics (Harris \& Bourne 2017), chemistry (Montella 2008), and financial derivatives (Qian et al. 2018). Based on the computation times, simplicity, robustness, and speed of convergence, the performance of this algorithm is very efficient in estimating the ruin probability (Usábel 1999).

The Gaver-Stehfest algorithm is an extrapolation of prior sequences derived by Stehfest (1970) that we will use to estimate the moment functions $\mu_{z}^{(m)}(T)$ :

$$
\mu_{z}^{(m)}(T) \approx I_{k}(T)=\frac{\ln (2)}{T} \sum_{k=1}^{n} a_{k} M\left(k \frac{\ln (2)}{T}\right), n \geq 2, T>0,
$$

whereby the coefficient $a_{k}$ is defined as:

$$
a_{k}:=\frac{(-1)^{k+n / 2}}{(n / 2) !} \sum_{j=\left\lfloor\frac{k+1}{2}\right]}^{k \wedge n / 2} j^{n / 2+1}\left(\begin{array}{l}
n / 2 \\
j
\end{array}\right)\left(\begin{array}{l}
2 j \\
j
\end{array}\right)\left(\begin{array}{l}
j \\
k-j
\end{array}\right),
$$

for even values of $n$.

Under this algorithm, we approximate an inverse of a Laplace transform using a sample $I_{k}(T)$ given as:

$$
I_{k}(T)=\int_{0}^{\infty} \Delta_{k}(T, y) \mu_{z}^{(m)}(y) d y,
$$

with $k$ being the number of expansion terms (Krougly et al. 2017). For each $k$, the function $\Delta_{k}(T, y)$ forms a delta convergent sequence, which implies that $I_{k}(T)$ approaches $\mu_{z}^{(m)}(T)$ as $k$ increases (Davies \& Martin 1979):

$$
\lim _{k \rightarrow \infty} I_{k}(T)=\lim _{k \rightarrow \infty} \int_{0}^{\infty} \Delta_{k}(T, y) \mu_{z}^{(m)}(y) d y \rightarrow \mu_{z}^{(m)}(T), T>0 .
$$

The delta function, $\Delta_{k}(T, y)$,

$$
\Delta_{k}(T, y):=\left(\frac{\ln (2)}{T}\right) \frac{(2 k) !}{k !(k-1) !}\left(1-e^{-\frac{\ln (2)}{T} y}\right)^{k} e^{-\frac{\ln (2)}{T} k y}
$$

forms sequences of approximation as follows:

$I_{k}(T)=\frac{\ln (2)}{T} \frac{(2 k) !}{k !(k-1) !} \sum_{i=0}^{k}\left(\begin{array}{l}k \\ i\end{array}\right)(-1)^{i} M\left((k+i) \frac{\ln (2)}{T}\right), k \geq 1, T>0$,

where $M(\rho)$ is the Laplace transform of $\mu_{z}^{(\mathrm{m})}(T)$. Equation (24) is obtained by expanding $\left(1-e^{-\frac{\ln (2)}{T} y}\right)^{k}$ in (23) using binomial theorem (Gaver 1966).

By working on the numerical inversion of the Laplace transform using the Gaver-Stehfest algorithm, we are left with solving the straightforward function $g^{(m)}$ $(T)$, making the computation more efficient despite using a Weibull inter-waiting time.

\section{RESULTS AND DisCUSSION}

\section{VERIFICATION OF THE LAPLACE INVERSION}

We numerically solve the first and second moments to verify that our derivation in the previous section is correct. We compare the results obtained using GaverStehfest algorithm with the results in Mohd Ramli and Jang (2014) under the Neumann series method with $\theta=$ 0 and \pm 0.9 with Poisson counting process. We assume exponential claims size with mean $1 / \alpha=0.1$, Weibull inter-claim time with shape parameter $\lambda=1$, scale parameter $\beta=1$, instantaneous rate of net interest $\delta=4 \%$ and $T=5$ under the $F G M$ copula (Table 1).

We confirm that the computations under both methods yield the same results for $\lambda=1$. The GaverStehfest method allows us to compute the first moment for an almost perfect correlation of $\theta_{F G M}= \pm 0.999$, as opposed to only up to $\theta_{F G M}= \pm 0.95$ when the computation was done using the long-winded expressions as in Mohd Ramli and Jang (2014). 
TABLE 1. Moments of the aggregate discounted claims under the FGM copula claim with claims size $X \sim$

$\operatorname{Exp}(\alpha=10)$ and inter-claim arrival time $W \sim$ Weibull $(\lambda=1, \beta=1)$

\begin{tabular}{ccc}
\hline$\theta_{F G M}$ & $\mu_{z}^{(1)}(5)$ & $\mu_{z}^{(2)}(5)$ \\
-0.999 & 0.477657 & 0.334509 \\
-0.995 & 0.477559 & 0.334318 \\
-0.99 & 0.477436 & 0.334078 \\
-0.95 & 0.476456 & 0.332163 \\
-0.9 & 0.475231 & 0.329774 \\
-0.5 & 0.465427 & 0.310877 \\
0 & 0.453173 & 0.287786 \\
0.5 & 0.440919 & 0.265283 \\
0.9 & 0.431115 & 0.247706 \\
0.95 & 0.429890 & 0.245535 \\
0.99 & 0.428910 & 0.243803 \\
0.995 & 0.428787 & 0.243586 \\
0.999 & 0.428689 & 0.243413 \\
\hline
\end{tabular}

\section{MOMENTS AND PREMIUM COMPUTATION UNDER VARIOUS WEIBULL INTER-CLAIM TIME SHAPE PARAMETER $(\lambda)$}

We examine the effect of dispersion of the counting process on the moments of the aggregate claims and its variance. To do so, we first note that the Weibull counting process exhibits overdispersion when $\lambda \in(0,1)$, underdispersion when $\lambda \in(1, \infty)$, and equidispersion when $\lambda=1$ (McShane et al. 2008). We first use (1) and (2) to compute the mean and variance of the Weibull count models (Weibull $(\lambda, \beta)$ ). For each pair of equi- and under-/overdispersed count model, the parameters $\lambda$ and $\beta$ are chosen in such a way that both pairs of the counting processes have an equal mean but different variance. We then evaluate the moments of the risk portfolio $Z$ and present the results in Tables 2 and 3.
Table 2 shows that although both counting processes have an equal mean of 0.506 , the variance under the overdispersed scenario (Weibull $(\lambda=0.5, \beta=5$ ) is higher than the variance under the equidispersed counterpart (Weibull $_{C}(\lambda=0.5, \beta=9.874)$. Figure 1 shows that the probability of two or more claims occurring when the counting process is overdispersed is higher than the probability under the equidispersed scenario. Therefore, there is a higher chance of more claims coming in the fixed time interval when the counting process is overdispersed. This is reflected in the value of moments and variance of the risk portfolio, $Z$ which are higher under the overdispersed scenario than the equidispersed counterpart. In addition, the difference between the values returned by the mean and variance as $\theta$ changes from -0.999 to 0.999 (spread), are also wider under the overdispersed case. 
TABLE 2. Moments, variance and premium computation of the aggregate discounted claims under the FGM copula with claims size $X \sim \operatorname{Exp}(0.1)$ for overdispersed and equidispersed Weibull count models when $T=5$

\begin{tabular}{ccccccccc}
\hline \multicolumn{3}{c}{ Overdispersed } & & \multicolumn{3}{c}{ Equidispersed } \\
\multicolumn{3}{c}{ Weibull $_{C}(\lambda=0.5, \beta=5)$} & & \multicolumn{3}{c}{ Weibull $_{C}(\lambda=1, \beta=9.874)$} \\
$\theta$ & $\mu_{z}^{(1)}(5)$ & $\mu_{z}^{(2)}(5)$ & Variance & Premium & $\mu_{z}^{(1)}(5)$ & $\mu_{z}^{(2)}(5)$ & Variance & Premium \\
\hline-0.999 & 14.733 & 627.091 & 410.021 & 16.758 & 6.055 & 163.521 & 126.860 & 7.181 \\
-0.995 & 14.723 & 626.284 & 409.532 & 16.746 & 6.049 & 163.273 & 126.684 & 7.174 \\
-0.990 & 14.710 & 625.286 & 408.899 & 16.732 & 6.042 & 162.964 & 126.463 & 7.166 \\
-0.950 & 14.607 & 617.288 & 403.923 & 16.617 & 5.983 & 160.496 & 124.701 & 7.100 \\
-0.900 & 14.478 & 607.344 & 397.722 & 16.473 & 5.910 & 157.424 & 122.501 & 7.016 \\
-0.500 & 13.447 & 529.915 & 349.088 & 15.316 & 5.323 & 133.354 & 105.022 & 6.348 \\
0.000 & 12.159 & 438.466 & 290.627 & 13.864 & 4.589 & 104.532 & 83.469 & 5.503 \\
0.500 & 10.871 & 352.939 & 234.772 & 12.403 & 3.856 & 77.115 & 62.247 & 4.645 \\
0.900 & 9.840 & 288.783 & 191.965 & 11.225 & 3.269 & 56.195 & 45.507 & 3.944 \\
0.950 & 9.711 & 281.031 & 186.725 & 11.078 & 3.196 & 53.643 & 43.429 & 3.855 \\
0.990 & 9.608 & 274.872 & 182.557 & 10.959 & 3.137 & 51.611 & 41.769 & 3.784 \\
0.995 & 9.596 & 274.106 & 182.033 & 10.945 & 3.130 & 51.358 & 41.562 & 3.775 \\
0.999 & 9.585 & 273.489 & 181.625 & 10.932 & 3.124 & 51.155 & 41.396 & 3.767 \\
\hline
\end{tabular}

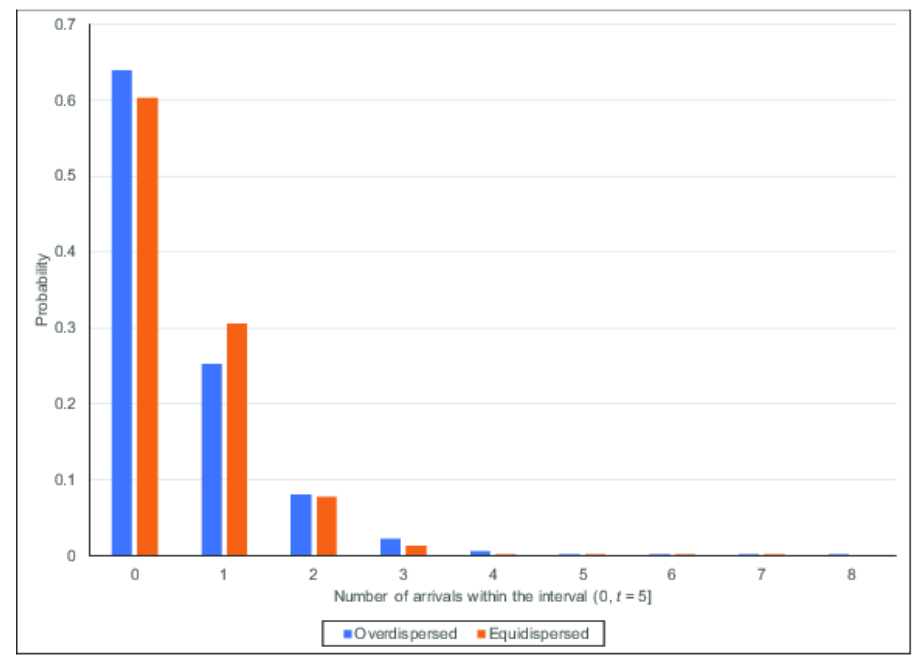

FIGURE 1. Histogram of overdispersed Weibull count model, Weibull $_{C}(\lambda=0.5, \beta=5)$, and equidispersed Weibull count model, Weibull $C(\lambda=1, \beta=9.874)$ when $T=5$ 
Similarly, Table 3 shows both underdispersed and equidispersed Weibull counting processes have equal mean value of 4.243 , with the variance of the underdispersed Weibull count model, Weibull ${ }_{C}=(\lambda=2, \beta=1.5)$, being lower than its mean. When the counting process is underdispersed, the moments of the risk portfolio $Z$ will be smaller than those under the equidispersion case. Figure 2 shows that the claim frequencies are less concentrated around the mean value of 4.243 under the equidispersed scenario. The wider spread of claim frequency implies a higher chance that six or more claims occurring under the equidispersed process as opposed to the underdispersed process within the fixed time interval of $T=5$. This is reflected in Table 3 by higher average value, second moment and variance of the aggregate discounted claims under the equidispersed case than the underdispersed counterpart. The spread in value for both mean and variance under the equidispersed case is higher as $\theta$ changes from -0.999 to 0.999 . We can see from Tables 2 and 3 that the numerical inversion of Laplace transform with Gaver-Stehfest algorithm allow the computation of first and second moments for $\theta_{F G M}= \pm 0.999$, even though the count model is not equidispersed.

With the computation of first and second moments, we can compute the loaded premium related to the risk profile of the insurance risk portfolio represented by $Z(t)$, where the dependence structure is described by the FGM copula. The premium computation, $\Pi$ according to the standard deviation premium principle is illustrated as following:

$$
\Pi(T)=\mathrm{E}[Z(T)]+\kappa \sqrt{\operatorname{Var}[Z(T)]},
$$

Tables 2 and 3 exhibit the results of the loaded premium for both overdispersed and equidispersed scenario with $\kappa=0.1$. It can be shown that the overdispersed case results in a higher premium than the equidispersed case, while the underdispersed case produces a lower premium to be paid by the insured than the equidispersed case.

TABLE 3. Moments, variance and premium computation of the aggregate discounted claims under the FGM copula with claims size $X \sim \operatorname{Exp}(0.1)$ for underdispersed and equidispersed Weibull count models when $T=5$

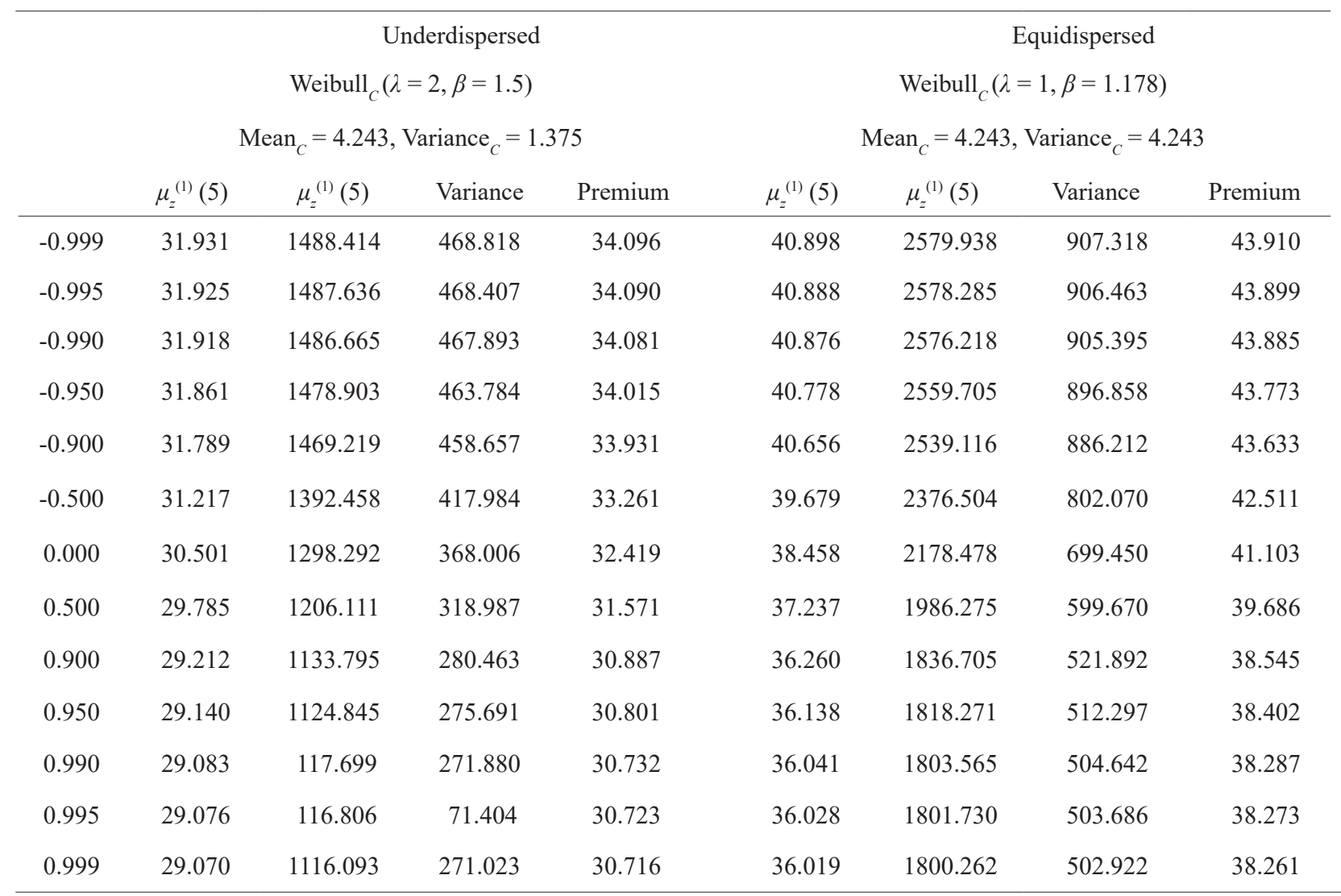




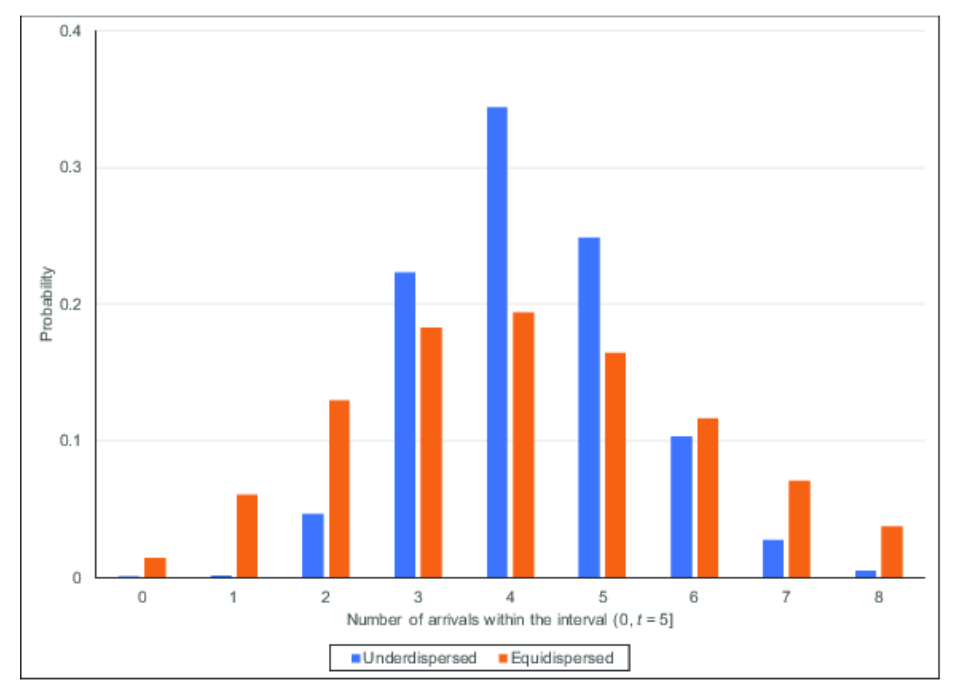

FIGURE 2. Histogram of underdispersed Weibull count model, Weibull $(\lambda=2, \beta=1.5)$, and equidispersed Weibull count model, Weibull ${ }_{C}(\lambda=1, \beta=1.178)$ when $T=5$

FIRST MOMENT UNDER VARIOUS WEIBULL INTER-CLAIM TIME SCALE PARAMETER AND CLAIMS SIZE PARAMETER

We now perform sensitivity analysis on the first moment of the aggregate discounted claim amount under the $F G M$ copula assuming an exponential claims size $X$ by varying the rate parameter of the claims size, $\alpha$, and the scale parameter of the inter-claim time, $\beta$ holding other parameters constant and $\lambda=2$. (Table $4 \&$ Figure 3 ). Table 4 shows that as $\beta$ increases from 0.005 to 2 , the rate of claim occurrence decreases and the marginal mean of the inter- claim time increases within a fixed time interval. This implies that insurers will have to wait longer until the next claim occurs, which implies less claim occurrence within a fixed time interval ( $T=5$ in this case) as the distribution is 'stretched'. Therefore, when other parameters are fixed, the average discounted claim amount decreases as $\beta$ increases. In addition, when $\alpha$ increases from 0.005 to 1.5 , the average claims size will decrease, and hence the first moment of the aggregate discounted claims will also decrease.

TABLE 4. Values of $\mu_{z}^{(1)}$ (5) for the risk portfolio with exponential claim size $(\alpha)$ and Weibull $(\lambda=2, \beta)$ inter-claim time when $\theta=-0.9$

\begin{tabular}{lcccccc}
\hline \multicolumn{7}{c}{$\alpha$} \\
\multicolumn{1}{c}{$\alpha$} & 0.005 & 0.01 & 0.05 & 0.1 & 1 & 2 \\
\hline 0.005 & $204,494.463$ & $102,223.815$ & $20,407.740$ & $10,180.726$ & 976.587 & 465.370 \\
0.01 & $102,247.232$ & $51,111.908$ & $10,203.870$ & $5,090.363$ & 488.293 & 232.685 \\
0.05 & $20,449.446$ & $10,222.382$ & $2,040.774$ & $1,018.073$ & 97.659 & 46.537 \\
0.1 & $10,224.723$ & $5,111.191$ & $1,020.387$ & 509.036 & 48.829 & 23.268 \\
1 & $1,022.472$ & 511.119 & 102.039 & 50.904 & 4.883 & 2.327 \\
1.5 & 681.648 & 340.746 & 68.026 & 33.936 & 3.255 & 1.551 \\
\hline
\end{tabular}




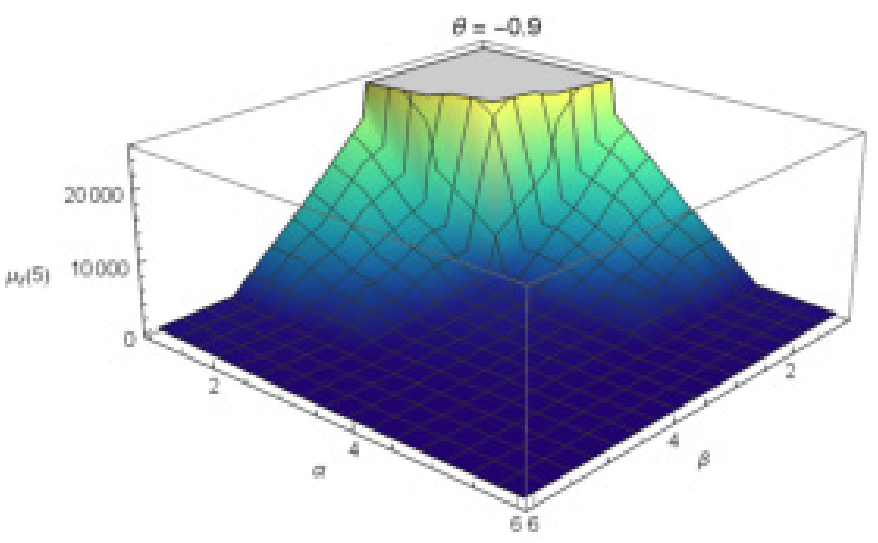

FIGURE 3. Sensitivity of $\mu_{z}^{(1)}(5)$ for the risk portfolio with exponential claim size $(\alpha)$ and Weibull $(\lambda=2, \beta)$ inter-claim time when $\theta=-0.9$

\section{MOMENTS AND VARIANCE OF THE COMPOUND DISTRIBUTION UNDER VARIOUS COPULA AND DIFFERENT INTER-CLAIM TIME}

In this section, we present the values of the mean and variance of the aggregate discounted claim, $Z$ under the Weibull inter-waiting time (IWT) assuming the dependency is captured by the FGM copula. We then compare the values to the mean and variance of the risk portfolio $Z$ under the exponential IWT assuming the dependency is captured by the FGM, Frank and HRT copula. The results are shown in Table 5. Setting $\lambda=1$, the Weibull count model under FGM copula reduces the inter-claim time distribution to exponential and hence, yields the same results as computed using the Poisson count model in Mohd Ramli et al. (2018). We change the shape parameter, $\lambda$ to 2 to allow for underdispersion effect and obtain a narrower spread of the moments and variance as opposed to an equidispersed IWT.

The value of the first moment in Table 5 does not vary much under FGM copula when we apply the changes on the inter-claim waiting time from Exponential to Weibull distribution as opposed to the changes made under different copula. The values of first moment under HRT copula shows the broadest spread as it is suitable in modeling the upper tail extreme events.

In contrast to the dependence structure in FGM copula, the Frank copula shows a positive correlation when the dependence parameter, and inversely correlated when when $\theta \in(1, \infty)$. The maximum value for both mean and variance for FGM and Frank copula are obtained when the claim size and inter-waiting time exhibit strong negative correlation. This is intuitively clear as negative dependence structure are represented by short inter-waiting time (or frequent claim occurrence) followed by large claim amount, as opposed to the positive dependence structure. Meanwhile, under HRT copula, as $\theta \rightarrow \infty$, the mean and variance converge to the 453.17 and $82,419.93$, respectively, which is the value of the mean and variance when the variables are independent under FGM (when $\theta$ $=0$ ) and Frank copula (when $\theta=1$ ).

TABLE 5. Values of $\mu_{z}^{(1)}(5)$ and $\operatorname{Var}(5)$ for various copula with $T=5, \alpha=0.01, \beta=1, \beta^{*}=1.1821$ and $\delta=0.04$

\begin{tabular}{lcccccccccc}
\hline & \multicolumn{9}{c}{ FGM } \\
& \multicolumn{2}{c}{$\operatorname{IWT}_{\text {Weibul }\left(\lambda=2, \beta^{*}\right)}$} & \multicolumn{2}{c}{$\operatorname{IWT}_{\text {Weibull }(\lambda=1)}$} & \multicolumn{2}{c}{ Frank } & \multicolumn{2}{c}{$\operatorname{IWT}_{\text {exp }}$} & \multicolumn{2}{c}{ HRT } \\
\multicolumn{1}{c}{$\theta$} & $\mu_{z}^{(1)}(5)$ & $\operatorname{Var}(5)$ & $\mu_{z}^{(1)}(5)$ & $\operatorname{Var}(5)$ & $\theta$ & $\mu_{z}^{(1)}(5)$ & $\operatorname{Var}(5)$ & $\mu_{z}^{(1)}(5)$ & $\operatorname{Var}(5)$ \\
\hline-0.999 & 410.9 & $59,939.2$ & 477.6 & $106,351.8$ & 0.005 & 400.6 & $35,906.6$ & 10.4 & $3,704.4$ \\
-0.95 & 410.2 & $59,314.6$ & 476.4 & $105,151.7$ & 0.05 & 418.7 & $51,061.4$ & 249.1 & $67,472.0$ \\
-0.9 & 409.5 & $58,678.2$ & 475.2 & $103,929.5$ & 0.5 & 444.6 & $74,366.7$ & 374.0 & $19,574.0$ \\
-0.5 & 403.8 & $53,622.7$ & 465.4 & $94,253.7$ & 1 & 453.1 & $82,420.0$ & 392.1 & $33,255.1$ \\
0 & 396.6 & $47,393.0$ & 453.1 & $82,420.2$ & 10 & 478.4 & $107,416.3$ & 443.7 & $74,181.6$ \\
0.5 & 389.4 & $41,262.9$ & 440.9 & $70,874.4$ & 500 & 501.3 & $131,596.3$ & 452.9 & $82,248.9$ \\
0.9 & 383.6 & $36,430.6$ & 431.1 & $61,845.8$ & 5000 & 506.8 & $137,716.4$ & 453.1 & $82,402.8$ \\
0.95 & 382.9 & $35,831.0$ & 429.8 & $60,729.5$ & $100 \mathrm{k}$ & 510.5 & $141,886.9$ & 453.1 & $82,419.1$ \\
0.999 & 382.2 & $35,244.4$ & 428.6 & $59,638.7$ & $\infty$ & 516.0 & $147,815.5$ & 453.1 & $82,419.9$ \\
\hline Spread & 28.7 & $24,694.8$ & 48.9 & $46,713.0$ & & 115.4 & $111,908.9$ & 442.7 & $78,715.5$ \\
\hline
\end{tabular}




\section{CONCLUSION}

In this study, we attempt to accommodate count data with unequal mean and variance, which is a common scenario in applied data analysis. The proposed model generalizes the Poisson risk model and is able to deal with the cases when the inter-claim arrival time data are underdispersed or overdispersed. Additionally, the use of the Gaver-Stehfest algorithm to solve the numerical Laplace inversion of its first two moments allows a more robust computation, while the dependency between the claim size and the interclaim arrival time is being captured by an FGM copula. The comparison of the recursive moments of the risk process when the Weibull count process is underdispersed, equidispersed and overdispersed implies that when claims arrive at times that vary more than is expected, insured lives are expected to pay higher premium, ceteris paribus. The sensitivity analysis conducted also showed that the behaviour of the average aggregate discounted claims is inversely related to the behaviour of the Weibull scale parameter and the claim size rate parameter examined. Upon comparison of the Weibull risk process and an equivalent Poisson risk process, the study also shows that the FGM copula produce the lowest and the narrowest range of moment values, followed by the HRT and Frank copula which may be more appropriate in modeling the upper tail extreme events.

\section{ACKNOWLEDGEMENTS}

The authors gratefully acknowledge the Malaysian Ministry of Education for the support provided via the grant FRGS/1/2016/STG06/UKM/03/1.

\section{REFERENCES}

Albrecher, H., Bladt, M. \& Vatamidou, E. 2020. Efficient simulation of ruin probabilities when claims are mixtures of heavy and light tails. Methodology and Computing in Applied Probability 43: 1-19.

Balakrishna, N. \& Lai, C.D. 2009. Distributions expressed as copulas. In Continuous Bivariate Distributions. Berlin: Springer. pp. 67-103.

Bargès, M., Loisel, S., Cossette, H. \& Marceau, É. 2011. On the moments of aggregate discounted claims with dependence introduced by a FGM copula. ASTIN Bulletin 41(1): 215238.

Boshnakov, G., Kharrat, T. \& McHale, I.G. 2017. A bivariate Weibull count model for forecasting association football scores. International Journal of Forecasting 33(2): 458466.

Davies, B. \& Martin, B. 1979. Numerical inversion of the laplace transform: A survey and comparison of methods. Journal of Computational Physics 33(1): 1-32.
Delbaen, F. \& Haezendonck, J. 1987. Classical risk theory in an economic environment. Insurance Mathematics and Economics 6(2): 85-116.

Garrido, J., Genest, C. \& Schulz, J. 2016. Generalized linear models for dependent frequency and severity of insurance claims. Insurance: Mathematics and Economics 70: 205215.

Gaver, D.P. 1966. Observing stochastic processes, and approximate transform inversion. Operations Research 14(3): 444-459.

Harris, C.K. \& Bourne, S.J. 2017. Computing the distribution of pareto sums using laplace transformation and stehfest inversion. Pure and Applied Geophysics 174(5): 20392075.

Hua, L. 2015. Tail negative dependence and its applications for aggregate loss modeling. Insurance: Mathematics and Economics 61: 135-145.

Kamaruzaman, I.F., Wan Zin, W.Z. \& Mohd Ariff, N. 2019. A generalized bivariate copula for flood analysis in Peninsular Malaysia. Malaysian Journal of Fundamental and Applied Sciences 15(1): 38-49.

Krämer, N., Brechmann, E.C., Silvestrini, D. \& Czado, C. 2013. Total loss estimation using copula-based regression models. Insurance: Mathematics and Economics 53(3): 829-839.

Krougly, Z., Davison, M. \& Aiyar, S. 2017. The role of high precision arithmetic in calculating numerical laplace and inverse laplace transforms. Applied Mathematics 8(04): 562-589.

Kularatne, T.D., Li, J. \& Pitt, D. 2020. On the use of Archimedean copulas for insurance modelling. Annals of Actuarial Science 15(1): $1-25$.

Léveillé, G. \& Garrido, J. 2001. Recursive moments of compound renewal sums with discounted claims. Scandinavian Actuarial Journal 2001(2): 98-110.

Liu, H. 2019. Reliability and maintenance modeling for competing risk processes with Weibull inter-arrival shocks. Applied Mathematical Modelling 71: 194-207.

Mao, T. \& Yang, F. 2015. Risk concentration based on Expectiles for extreme risks under FGM copula. Insurance: Mathematics and Economics 64: 429-439.

McShane, B., Adrian, M., Bradlow, E.T. \& Fader, P.S. 2008. Count models based on weibull interarrival times. Journal of Business and Economic Statistics 26(3): 369-378.

Mohd Ramli, S.N. \& Jang, J. 2020. Defaultable bond pricing under the jump diffusion model with copula dependence structure. Sains Malaysiana 49(4): 941-952.

Mohd Ramli, S.N. \& Jang, J. 2014. Neumann series on the recursive moments of copula-dependent aggregate discounted claims. Risks 2(2): 195-210.

Mohd Ramli, S.N., Mohamed Rozali, N.A., Syed Yusoff Alhabshi, S.F. \& Hashim, I. 2018. Laplace transform on the recursive moments of copula-dependent aggregate discounted claims. AIP Conference Proceedings 2184: 050017. 
Montella, C. 2008. LSV modelling of electrochemical systems through numerical inversion of Laplace transforms. I - the GS-LSV algorithm. Journal of Electroanalytical Chemistry 614(1-2): 121-130.

MunichRe. 2018. NatCatSERVICE. http://natcatservice. munichre.com. Accessed on February 14, 2018.

Nelsen, R.B. 2006. An Introduction to Copulas. In Springer Series in Statistics. Berlin: Springer. pp. 51-108.

Qian, L., Jin, Z., Wang, W. \& Chen, L. 2018. Pricing dynamic fund protections for a hyperexponential jump diffusion process. Communications in Statistics - Theory and Methods 47(1): 210-221.

Shamiri, A., Hamzah, N.A. \& Pirmoradian, A. 2011. Tail dependence estimate in financial market risk management: Clayton-Gumbel Copula approach. Sains Malaysiana 40(8): 927-935.

Shi, P., Feng, X. \& Ivantsova, A. 2015. Dependent frequencyseverity modeling of insurance claims. Insurance: Mathematics and Economics 64: 417-428.

Stehfest, H. 1970. Algorithm 368: Numerical inversion of Laplace transforms [D5]. Communications of the ACM 13(1): 47-49.

Tosunoglu, F. \& Kisi, O. 2016. Joint modelling of annual maximum drought severity and corresponding duration. Journal of Hydrology 543(Part B): 406-422.

Usábel, M. 1999. Calculating multivariate ruin probabilities via Gaver-Stehfest inversion technique. Insurance: Mathematics and Economics 25(2): 133-142.

Venter, G.G. 2002. Tails of copulas. In Proceedings of the Casualty Actuarial Society 89: 68-113.
Waters, H.R. 1983. Probability of ruin for a risk process with claims cost inflation. Scandinavian Actuarial Journal 1983(3): 148-164.

Woo, J.K. \& Cheung, E.C.K. 2013. A note on discounted compound renewal sums under dependency. Insurance: Mathematics and Economics 52(2): 170-179.

Yang, H. \& Zhang, L. 2001. On the distribution of surplus immediately before ruin under interest force. Statistics and Probability Letters 29(2): 247-255.

Siti Norafidah Mohd Ramli \& Sharifah Farah Syed Yusoff Alhabshi*

Department of Mathematical Sciences

Faculty of Science and Technology

Universiti Kebangsaan Malaysia

43600 UKM Bangi, Selangor Darul Ehsan

Malaysia

Nur Atikah Mohamed Rozali

Actuarial Services Department

Malaysian Reinsurance Berhad

11th Floor, Bangunan Malaysian Re.

No. 17, Lorong Dungun, Damansara Height

50490 Kuala Lumpur, Federal Territory

Malaysia

*Corresponding author; email: shfarah@ukm.edu.my

Received: 17 July 2020

Accepted: 16 November 2020 